\section{The American Board of Thoracic Surgery}

\section{ABTS Announcement}

The American Board of Thoracic Surgery's Maintenance of Certification program was adopted 7 years ago. Since that time, there has been a continuous evaluation in the Board's thinking about the overall process, based upon internal discussions and input from our diplomates.

These inputs resulted in our decision to migrate from a purely knowledge-based multiple-choice exam, using a Pearson Testing Center, to a Mastery Learning Process, using a SESATS format. Diplomates, enrolled in this year's (2015) 10 -year MOC process, will fulfill their Part III requirement by completion of a home or office-based secure learning exam, following the instructions on the ABTS Web site.

In brief, you will be directed to a secure Web site, administered by Software Secure. The only special computer hardware needed will be a camera for your home or office computer (most laptops now come with a built-in camera). Once logged in, you will be asked to verify your identity by holding up your driver's license with your picture next to your face. You will be visually monitored for the time you are logged onto the Web site.

There are 100 SESATS questions (primarily taken from SESATS X), based on your specialty designation (Adult Cardiac, General Thoracic, Cardiothoracic, and Congenital), that you will need to work through as instructed. The exam will now be modular and tailored to your practice-for example, if your practice is $100 \%$ adult cardiac, you will only have adult cardiac and critical care questions. You will have 15 hours with as many as 10 logins to complete the 100 questions during the months of September and October 2015. For those diplomates who have used SESATS in the past, the process of working through the questions is the same. For those who aren't familiar with SESATS, it might be beneficial to purchase and download SESATS X and work through the specialty-specific module. This preparation will give you familiarity with the process. While SESATS X may be helpful preparation, it is not required.

The goal of this exam is to provide a learning opportunity using judgement and decision making as well as knowledge. There is no grade involved, but you will be given the percentage of questions you answered correctly on the first try.

Not passing this exam would result from either not completing the 100 questions in the 15-hour and 10-login limit or by rushing through the questions without reading the critique. The Board and MOC Committee believe that reading the critique is key to the learning process using SESATS. The Software Secure reporting system will allow us to verify the pace of completion and thus limit the passing grades to those who earnestly participate in the process.

The Board sincerely hopes that this pilot of life-long learning is viewed favorably by our diplomates. If the diplomates find this form of learning better than the previous approach that used a secured multiple-choice test administered in a remote testing center, the Board will continue with this new strategy and refine SESATS as we go forward to assure that new standards of care are communicated to members of the ABTS community as part of the MOC process. There will be a brief survey following the last SESATS question, which needs to be completed to officially finish the process.

Everyone at the ABTS thanks you for embracing the primary principle of MOC-life-long learning, which is consistent with our obligation to the public trust.

\section{ABTS Requirements for the 10-Year Milestone for Maintenance of Certification}

Diplomates of the American Board of Thoracic Surgery (ABTS) who plan to participate in the 10-Year Milestone for the Maintenance of Certification (MOC) process as CertifiedActive must hold a currently valid, full, and unrestricted license to practice medicine. Diplomates must provide delineation of privileges at a hospital(s) accredited by the JCAHO or other institutions judged acceptable by the Board. Diplomates must also submit letter(s) of reference documenting their level of clinical activity and stature within the surgical community from the VP of Medical Affairs and one other responsible member on staff at their principal hospital. In addition, a valid ABTS certificate is an absolute requirement for entrance into the MOC process. If your certificate has expired, the only pathway for renewal of a certificate is to take and pass the Part I (written) and the Part II (oral) certifying examinations.

The CME requirements are 150 Category I credits over a five-year period. At least half of these CME hours need to be in the broad area of thoracic surgery. Category II credits are not accepted. Interested individuals should refer to the Board's Web site (www.abts.org) for a complete description of acceptable CME credits.

This year, the Board has changed the format of the MOC exam. Instead of taking the MOC exam at a testing center, the Board wants Diplomates to be aware that they will be taking the exam on their personal or office computer. The Diplomate will need to have a Web camera that will work in conjunction with the software for security purposes. The Board is transitioning to using SESATS as the mastery 